\title{
Risks and benefits of citrate anticoagulation for continuous renal replacement therapy
}

\author{
HP Shum *, WW Yan, TM Chan
}

This article was published on 5 Dec 2014 at www.hkmj.org.

\section{A B S T R A C T}

Heparin, despite its significant side-effects, is the most commonly used anticoagulant for continuous renal replacement therapy in critical care setting. In recent years, citrate has gained much popularity by improving continuous renal replacement therapy circuit survival and decreasing blood transfusion requirements. However, its complex metabolic consequences warrant modification in the design of the citrate-based continuous renal replacement therapy protocol. With thorough understanding of the therapeutic mechanism of citrate, a simple and practicable protocol can be devised. Citratebased continuous renal replacement therapy can be safely and widely used in the clinical setting with appropriate clinical staff training.

Hong Kong Med J 2015;21:149-54

DOI: 10.12809/hkmj144330

${ }^{1}$ HP Shum *, FHKCP, FHKAM (Medicine)

${ }^{1}$ WW Yan, FHKCP, FHKAM (Medicine)

2 TM Chan, MD, FHKAM (Medicine)

Department of Intensive Care, Pamela Youde Nethersole Eastern Hospital, Chai Wan, Hong Kong

2 Department of Medicine, The University of Hong Kong, Queen Mary Hospital, Pokfulam, Hong Kong

* Corresponding author: shumhp@ha.org.hk

\section{Introduction}

Continuous renal replacement therapy (CRRT) is commonly used for the management of acute kidney injury in the intensive care unit (ICU) worldwide. Anticoagulation is necessary to prevent clotting of the extracorporeal circuit. Unfractionated heparin has the advantages of acceptable circuit life, low cost, easy monitoring and simple reversal, and hence, remains a popular choice. ${ }^{1,2}$ However, critically ill patients have various bleeding risks that may contraindicate the use of heparin. The contra-indications may include recent surgical procedures, multiple trauma, thrombocytopenia, and coagulation defects. ${ }^{3}$ Moreover, binding of heparin to endothelial antithrombin inhibits its anti-inflammatory actions and prevents local prostacyclin formation that, in turn, jeopardises micro-circulation. ${ }^{4,5}$ Hence, heparin use may be disadvantageous in patients with Gram-negative sepsis. ${ }^{4}$ Although implementation of an anticoagulation-free regimen is a safer alternative, circuit clotting occurs frequently, which not only increases treatment cost and downtime, but also increases the need of blood transfusion and the nursing workload. Among the various alternative anticoagulants like low-molecular-weight heparin, serine proteinase inhibitor nafamostat, prostacyclin, hirudin and direct thrombin inhibitor, citrate has gained popularity in recent years. This paper provides a general review on citrate use in CRRT and focuses on studies published in the past decade.

\section{Mechanism of action}

Citrate just mixes with the blood before it enters the CRRT circuit as illustrated in the commonly used citrate-based CRRT regimens (Figures 1 to 3). Citrate chelates the ionised calcium, which is essential for the normal coagulation cascade and results in inhibition of thrombin generation. An extracorporeal, post-filter, ionised calcium concentration of 0.25 to $0.35 \mathrm{mmol} / \mathrm{L}$ is effective to achieve the anticoagulation effect. The majority of citrate is removed by either filtration or dialysis with a sieving coefficient of one in both processes. ${ }^{6}$ The removal fraction varies from $20 \%$ to $80 \%$, depending on the blood flow rate, effluent flow rate, and CRRT modality. ${ }^{7,8}$ The remaining calcium-citrate product enters the systemic circulation and is metabolised in the liver, muscles, and kidneys to produce three molecules of bicarbonate for every molecule of citrate. Replacement infusion of calcium is commonly given to compensate the extracorporeal loss and to normalise a patient's systemic calcium level. ${ }^{8,9}$ The relative contra-indications for citrate-based CRRT include liver failure with or without cirrhosis, severe hypoxaemia, and after massive blood transfusion.

\section{Circuit survival}

Factors affecting the circuit life include a patient's clinical condition and coagulation status, the position and patency of the vascular access, the choice of anticoagulant, modality of CRRT, and filtration fraction. ${ }^{10,11}$ Most of the published randomised controlled trials (RCTs) indicate improved circuit survival with citrate versus heparin (Table $1^{12-17}$ ). Three meta-analyses have been published recently that summarise this issue. ${ }^{18-20}$ While Liao et $\mathrm{al}^{20}$ 


\section{枸格酸抗凝作連續性腎臟替代治療的風險及效益}

\section{沈海平、殷榮華、陳德茂}

肝素是連續性腎藏替代治療（CRRT）中最常用的抗凝血劑，然而與 其相關的副作用甚為顯著。枸柊酸抗凝可以改善CRRT使用壽命及降 低輸血需求, 因此枸椽酸近年來逐漸普及。設計枸椂酸CRRT方案時 要多加注意其複雜的代謝後果。通過深入了解其治療機制, 設計簡單 可行的CRRT方案及適當培訓臨床人員, 枸榢酸抗凝可安全及被廣泛 應用。

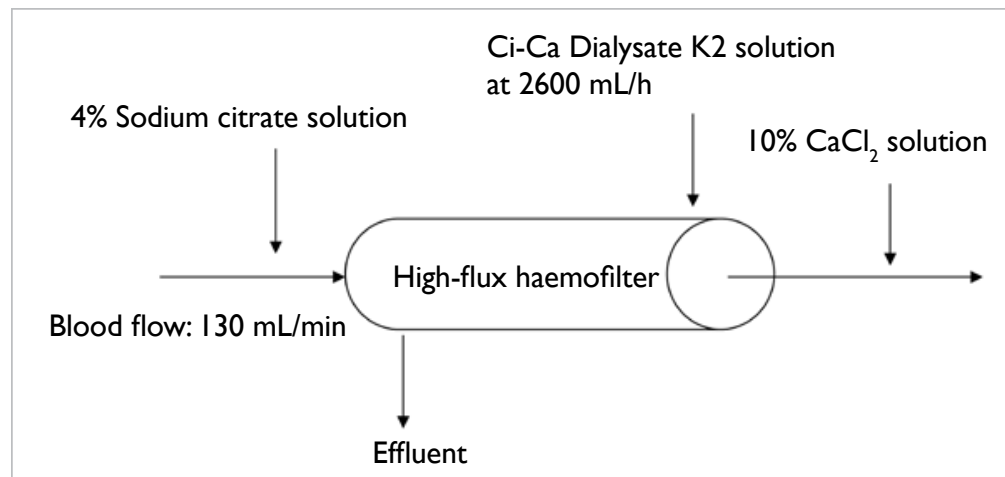

FIG I. Citrate-based continuous venovenous haemodialysis

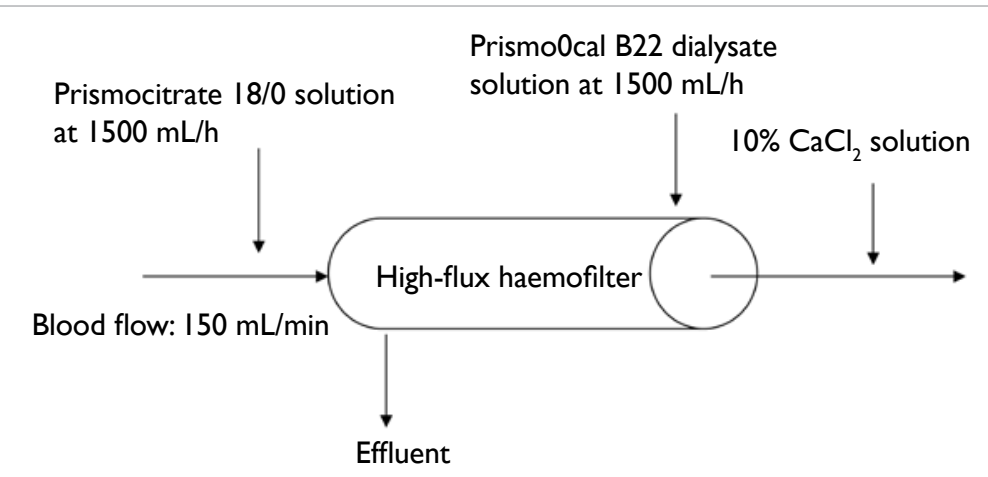

FIG 2. Citrate-based continuous venovenous haemodiafiltration

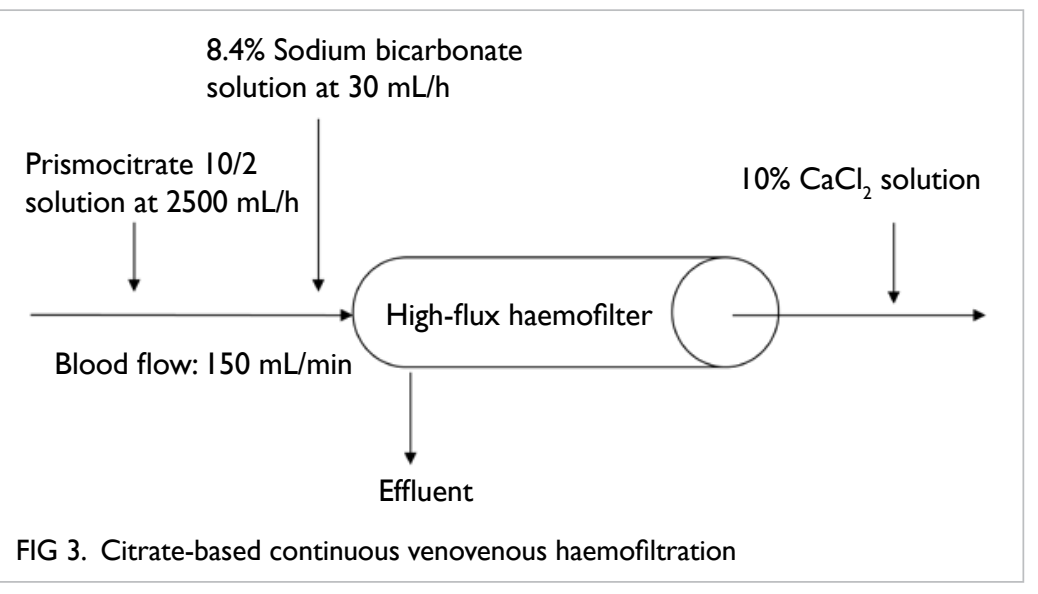

only focused on RCTs that compare unfractionated heparin with citrate, Zhang and Hongying ${ }^{18}$ and $\mathrm{Wu}$ et $\mathrm{a}^{19}$ also included studies on low-molecular-weight heparin and regional heparin. They concluded that circuit life with citrate was comparable ${ }^{19,20}$ or better (by a mean difference of 23.03 hours; $95 \%$ confidence interval, $0.45-45.61$ hours) than that with heparin. ${ }^{18}$ The main reason for the discrepancy between the findings by Zhang and Hongying ${ }^{18}$ (which showed more favourable circuit life for citrate group vs heparin group) and Wu et $\mathrm{al}^{19}$ (which showed comparable circuit life between citrate and heparin groups) was attributed to the study by Betjes et al, ${ }^{17}$ which did not report interquartile ranges of circuit survival. While Zhang and Hongying ${ }^{18}$ estimated the survival time in this study by Kaplan-Meier analysis, Wu et $\mathrm{al}^{19}$ excluded it from their circuit survival analysis. With the improved circuit life, citrate can decrease circuit downtime and minimise discrepancy between prescribed and delivered CRRT dose, achieve lower treatment cost, avoid unnecessary blood loss, and reduce nursing workload. In fact, the latest Kidney Disease Improving Global Outcomes Clinical Practice Guidelines recommended citrate as the anticoagulant of choice in patients requiring CRRT. $^{21}$

\section{Metabolic control}

Concerning reversal of metabolic acidosis and control of uraemia, most RCTs ${ }^{12,13,17}$ reported similar efficacy when comparing citrate- with heparinbased CRRT, except one study ${ }^{16}$ which was in favour of citrate. This might be explained by the longer circuit lifetime, which offered better uraemic toxin clearance.

\section{Bleeding events}

All RCTs, ${ }^{12,13,15-17}$ except one, ${ }^{14}$ showed a higher bleeding risk with heparin-based CRRT when compared with citrate anticoagulation (Table 1). All the three meta-analyse ${ }^{18-20}$ demonstrated a significantly lower incidence of bleeding in citratebased CRRT compared with heparin, with a pooled risk ratio ranging from 0.25 to 0.34 . However, the definition of bleeding events varied in all the included trials. Blood transfusion requirement was lower in the citrate group when compared with the unfractionated heparin group. ${ }^{20}$

\section{Mortality}

Three studies provided outcome information on mortality (Table 1). ${ }^{12,13,15}$ The study by Kutsogiannis et $\mathrm{al}^{15}$ was relatively small $(\mathrm{n}=30$, mortality rate of citrate group vs heparin group $=81 \%$ vs $71 \% ; \mathrm{P}=0.69$ ) and was not powered to detect survival difference. The single-centre study by Oudemans-van Straaten et $\mathrm{al}^{13}$ showed a mortality benefit at 3 months $(48 \%$ 
TABLE I. Characteristics and major findings of randomised controlled trials comparing regional citrate- and heparin-based continuous renal replacement therapy ${ }^{12-17}$

\begin{tabular}{|c|c|c|c|c|c|c|}
\hline & Hetzel et al ${ }^{12}$ & $\begin{array}{l}\text { Oudemans-van } \\
\text { Straaten et } \text { al }^{13}\end{array}$ & Fealy et al $^{14}$ & Betjes et al ${ }^{17}$ & 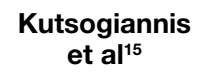 & Monchi et al ${ }^{16}$ \\
\hline Year of publication & 2011 & 2009 & 2007 & 2007 & 2005 & 2004 \\
\hline Centre & Multi & Single & Single & Single & Multi & Single \\
\hline No. of patients & $\begin{array}{l}\mathrm{C}: 87 \\
\mathrm{H}: 83\end{array}$ & $\begin{array}{l}\text { C: } 97 \\
H: 103\end{array}$ & $\begin{array}{l}\text { C: } 10 \\
H: 10\end{array}$ & $\begin{array}{l}\text { C: } 21 \\
H: 27\end{array}$ & $\begin{array}{l}\text { C: } 16 \\
H: 14\end{array}$ & $\begin{array}{l}\mathrm{C}: 8 \\
\mathrm{H}: 12\end{array}$ \\
\hline Age (years) & $\begin{array}{l}C: 62^{\star} \\
H: 65^{\star}\end{array}$ & $\begin{array}{l}\mathrm{C}: \text { 73† } \\
\mathrm{H}: \text { 73† }\end{array}$ & C \& H: $71 \dagger$ & $\begin{array}{l}C: 58^{\star} \\
H: 55^{\star}\end{array}$ & $\begin{array}{l}\mathrm{C}: 67^{\star} \\
\mathrm{H}: 64^{\star}\end{array}$ & $\begin{array}{l}\mathrm{C}: 67 \dagger \\
\mathrm{H}: 64 \dagger\end{array}$ \\
\hline Sepsis & $\begin{array}{l}\mathrm{C}: 77 \% \\
\mathrm{H}: 74 \%\end{array}$ & $\begin{array}{l}\text { C: } 43 \% \\
H: 49 \%\end{array}$ & C \& H: $30 \%$ & $\begin{array}{l}\text { C: } 76 \% \\
H: 59 \%\end{array}$ & $\begin{array}{l}\text { C: } 31 \% \\
H: 43 \%\end{array}$ & $\begin{array}{l}\text { C: } 50 \% \\
H: 42 \%\end{array}$ \\
\hline Treatment & Citrate vs UFH & Citrate vs LMWH & Citrate vs regional UFH & Citrate vs UFH & Citrate vs UFH & Citrate vs UFH \\
\hline Circuit lifespan (hours) & $\begin{array}{l}\mathrm{C}: 38 \\
\mathrm{H}: 26\end{array}$ & $\begin{array}{l}\text { C: } 27 \\
H: 26\end{array}$ & $\begin{array}{l}\text { C: } 17 \\
\mathrm{H}: 13\end{array}$ & $\begin{array}{l}\mathrm{C}: 36 \\
\mathrm{H}: 38\end{array}$ & $\begin{array}{l}\text { C: } 124 \\
H: 38\end{array}$ & $\begin{array}{l}\mathrm{C}: 70 \\
\mathrm{H}: 40\end{array}$ \\
\hline Control of acidosis & Similar & Similar & NR & Similar & NR & Similar \\
\hline Control of uraemia & Similar & Similar & NR & Similar & NR & In favour of citrate \\
\hline Mortality & $\begin{array}{l}\text { C: } 47 \% \\
\mathrm{H}: 41 \%\end{array}$ & $\begin{array}{l}\text { C: } 42 \% \\
H: 57 \%\end{array}$ & NR & NR & $\begin{array}{l}\text { C: } 81 \% \\
H: 71 \%\end{array}$ & NR \\
\hline Renal recovery & NR & $\begin{array}{l}\text { C: } 69 \% \\
H: 52 \%\end{array}$ & NR & NR & NR & NR \\
\hline Bleeding events & $\begin{array}{l}\text { C: } 6 \% \\
H: 15 \%\end{array}$ & $\begin{array}{l}\text { C: } 6 \% \\
H: 16 \%\end{array}$ & $\begin{array}{l}\text { C: } 0 \% \\
H: 0 \%\end{array}$ & $\begin{array}{l}\text { C: } 0 \% \\
H: 33 \%\end{array}$ & $\begin{array}{l}\text { C: } 6 \% \\
H: 57 \%\end{array}$ & $\begin{array}{l}\text { C: } 0 \% \\
H: 8 \%\end{array}$ \\
\hline Metabolic alkalosis & Similar & $\begin{array}{l}\text { C: } 9 \% \\
H: 19 \%\end{array}$ & NR & $\begin{array}{l}\text { C: } 0 \% \\
H: 7 \%\end{array}$ & $\begin{array}{l}\text { C: } 6 \% \\
H: 0 \%\end{array}$ & $\begin{array}{l}\text { C: } 13 \% \\
H: 0 \%\end{array}$ \\
\hline Hypocalcaemia & $\begin{array}{l}\text { C: } 1 \% \\
H: 0 \%\end{array}$ & $\begin{array}{l}\text { C: } 6 \% \\
H: 2 \%\end{array}$ & NR & $\begin{array}{l}\text { C: } 9 \% \\
\text { H: } 0 \%\end{array}$ & $\begin{array}{l}\text { C: } 6 \% \\
\text { H: } 0 \%\end{array}$ & $\begin{array}{c}\text { C: } 13 \% \\
\text { H: } 0 \%\end{array}$ \\
\hline
\end{tabular}

Abbreviations: $\mathrm{C}=$ regional citrate group; $\mathrm{H}=$ heparin group; LMWH = low-molecular-weight heparin; $\mathrm{NR}=$ not reported; UFH = unfractionated heparin

* Mean age

† Median age

vs $63 \%$ respectively; $\mathrm{P}=0.03)$ when comparing citrate with low-molecular-weight heparin. Mortality was mainly reduced in surgical patients, those with sepsis, those younger ( $<73$ years), and in patients with higher Sepsis-related Organ Failure Assessment scores ( $>11$ points). The study speculated that citrate, apart from being an excellent anticoagulant for CRRT, might have immunomodulatory actions that suppress inflammation, thus, leading to a survival benefit in critically ill patients. ${ }^{13}$ However, a subsequent multicentre study by Hetzel et $\mathrm{al}^{12}$ failed to demonstrate such benefit. While Hetzel et $\mathrm{al}^{12}$ used unfractionated heparin, Oudemans-van Straaten et $\mathrm{al}^{13}$ used a low-molecular-weight heparin preparation. Hetzel et al ${ }^{12}$ also included subjects who were younger and more septic. The discrepancy in clinical background and the different mode of anticoagulation might explain the difference in the observed results. It was important to note that both studies were not sufficiently powered to ascertain survival benefit of regional citrate anticoagulation, and mortality rate was not the primary end-point. A properly powered, well-designed RCT is required to clarify this issue.

\section{Side-effects}

Citrate anticoagulation has complex metabolic consequences due to its physiochemical property. Apart from being an anticoagulant, it also serves as a pH buffer, chelating agent, and a source of energy and sodium.

\section{Citrate toxicity}

A recent pharmacokinetic study showed that citrate clearance is not impaired in critically ill patients. ${ }^{22}$ However, reduced metabolism of citrate occurs in patients with chronic liver disease, ischaemic hepatitis, hypoxia and impaired muscle perfusion, which are commonly found in the ICU setting. Citrate accumulation results in ionised hypocalcaemia and acidosis, which cause hypotension due to decreased myocardial contractility and vascular hypotonia. A paradoxical increase in total calcium concentration often occurs due to increased citrate-bound calcium, as well as the increased use of calcium replacement in response to ionised hypocalcaemia. The totalto-ionised calcium ratio is, therefore, an important marker to detect citrate accumulation. ${ }^{23,24}$ An 
elevated ratio of $>2.25$ should alert the clinician to the possibility of citrate accumulation. Impaired citrate metabolism is an independent risk factor for mortality. A ratio of $\geq 2.4$ independently predicted a 33.5 -fold increase in 28 -day mortality rate in critically ill patients. ${ }^{25}$ There was also a significant correlation between total-to-ionised calcium ratio and the severity of critical illness. Citrate toxicity should be suspected, based on the presence of the following three observations, namely, elevated total-to-ionised calcium ratio of $>2.25$, increased use of calcium replacement, and increasing metabolic acidosis. Clinically, patients may present with symptoms of hypocalcaemia like circumoral paraesthesia, carpopedal spasm, generalised tetany, and hyper-reflexia.. ${ }^{26}$ Prolonged QT interval may follow by the development of Torsades de pointes or ventricular arrhythmia in untreated patients. ${ }^{26}$ Confirmation of citrate intoxication can only be done by checking citrate concentration in blood, which is not readily available in most hospital laboratories. Therefore, clinical symptoms and signs are suggestive but not diagnostic of citrate toxicity. In highly suspicious cases, citrate infusion should be stopped immediately, followed by intravenous calcium injection. Continuous renal replacement therapy could be resumed using citrate-free regimen after initial stabilisation. Despite the potential risks associated with citrate toxicity, CRRT with citrate anticoagulation is considered feasible in patients with liver impairment, ${ }^{27}$ provided that careful monitoring of calcium level and meticulous titration are ensured. Citrate accumulation should be minimised with the reduction in citrate infusion, increase in effluent flow to promote citrate clearance, adequate calcium replacement to counteract hypocalcaemia, and supplementation with extra bicarbonate to correct acidosis.

\section{Metabolic derangement}

Recent meta-analyses showed no significant difference in the incidence of metabolic alkalosis in citrate groups compared with heparin groups in patients with normal metabolism. ${ }^{19,20}$ Hypernatraemia is a problem commonly associated with the use of concentrated citrate solution (4\% trisodium citrate solution has $544 \mathrm{mmol} / \mathrm{L}$ sodium while Anticoagulant Citrate Dextrose Solution A [ACDA] has $224 \mathrm{mmol} / \mathrm{L}$ sodium). Adoption of a slightly hyponatraemic replacement or dialysate solution in the CRRT regimen may be a remedy to this problem. Alternatively, normonatraemic citrate solution may be used, for instance, Prismocitrate 18/0 or Prismocitrate 10/2 (Gambro Hospal, Stockholm, Sweden), which serves as both an anticoagulant and a source of buffer for predilutional treatment. ${ }^{28,29}$ The drawback of this method is that it does not guarantee a fixed relationship between citrate and blood flow.
This is due to the fact that the amount of replacement fluid entering the circuit is dependent on filtrate flow and the desired amount of fluid removal, which are prone to variations. The varying citrate concentration may consequently exert a negative effect on the circuit survival time. This issue can be resolved by fixing the flow ratio between blood and the citrate-containing substitution fluid. Citrate binds to magnesium, resulting in excessive loss in filtrate and causing hypomagnesaemia, which in turn decreases the release of parathyroid hormone, promotes hypokalaemia, and induces tetany as well as cardiac arrhythmia. Monitoring and replacement of magnesium should be done regularly.

\section{Energy gain}

Citrate also serves as a source of energy with 0.59 $\mathrm{kcal} / \mathrm{mmoL}$ and can enter cells without insulin. The bioenergetic gain of citrate-anticoagulated CRRT is not limited to citrate itself, but is also contributed by glucose (in ACDA) and lactate (in replacement or dialysate solution). The energy delivered can differ substantially between modalities, even with comparable doses. ${ }^{30}$ Such information should, therefore, be taken into account when nutritional needs are being calculated.

\section{Treatment cost}

The composition of commonly used fluid for CRRT is shown in Table 2. Using average filter life (citrate vs heparin $=52$ hours vs 30 hours) calculated based on previously published RCTs (Table 1), the total treatment cost for citrate-based CRRT lasting for 72 hours is around HK\$10 000 (using continuous venovenous haemodiafiltration with $1250 \mathrm{~mL} / \mathrm{h}$ prefilter citrate containing replacement solution plus $1250 \mathrm{~mL} / \mathrm{h}$ dialysate flow rate and two haemofilter/ circuit changes within 72 hours of treatment). The cost is similar to that of heparin-based regimen (using continuous venovenous haemodiafiltration with $1250 \mathrm{~mL} / \mathrm{h}$ post-filter replacement solution plus $1250 \mathrm{~mL} / \mathrm{h}$ dialysate flow rate and three haemofilter/ circuit changes within 72 hours of treatment).

\section{Future development}

\section{Development of fluid for citrate-based continuous renal replacement therapy}

The setup of regional citrate anticoagulant with conventional CRRT machines was more complicated compared with other anticoagulants. Since 1995, citrate in the form of ACDA had been the default anticoagulation method for CRRT in our unit, as described by Leung and Yan. ${ }^{31}$ The solutions for replacement are customised (with low bicarbonate and sodium level) as a concentrated citrate solution will provide extra sodium and bicarbonate load. Reconstitution of this customised replacement fluid 
TABLE 2. Composition of fluids available in Hong Kong for continuous renal replacement therapy

\begin{tabular}{|c|c|c|c|c|c|c|c|c|c|c|c|c|c|}
\hline & $\begin{array}{c}\mathrm{Na} \\
\text { (mmol/ } \\
\text { L) }\end{array}$ & $\underset{\substack{\mathrm{Kmol} / \\
\mathrm{L}}}{\mathrm{K}}$ & $\underset{\text { (mmol/ }}{\mathrm{Ca}}$ & $\underset{\text { (mmol/ }}{\mathrm{Mg}}$ & $\begin{array}{c}\mathrm{Cl} \\
(\mathrm{mmol} / \mathrm{L})\end{array}$ & $\begin{array}{l}\text { Lactate } \\
\text { (mmol/L) }\end{array}$ & $\begin{array}{c}\text { Acetate } \\
\text { (mmol/ } \\
\text { L) }\end{array}$ & $\begin{array}{c}\text { Bicar- } \\
\text { bonate } \\
\text { (mmol/ } \\
\text { L) }\end{array}$ & $\begin{array}{c}\text { Citrate } \\
\text { (mmol/ } \\
\text { L) }\end{array}$ & $\begin{array}{c}\text { Citric } \\
\text { acid } \\
(\mathrm{mmol} / \\
\mathrm{L})\end{array}$ & $\begin{array}{c}\text { Glucose } \\
\text { (g/L) }\end{array}$ & $\begin{array}{c}\mathrm{HPO}^{2-} \\
\text { (mmol/L) }\end{array}$ & $\begin{array}{l}\text { Osmol- } \\
\text { arity } \\
\text { (mOsm/L) }\end{array}$ \\
\hline FMC multiBic (free $\mathrm{K}^{+}$) & 140 & 0 & 1.5 & 0.5 & 109 & 0 & 0 & 35 & 0 & 0 & 1 & 0 & 290 \\
\hline FMC multiBic $\left(\mathrm{K}^{+} 2\right)$ & 140 & 2 & 1.5 & 0.5 & 111 & 0 & 0 & 35 & 0 & 0 & 1 & 0 & 294 \\
\hline FMC multiBic $\left(\mathrm{K}^{+} 3\right)$ & 140 & 3 & 1.5 & 0.5 & 112 & 0 & 0 & 35 & 0 & 0 & 1 & 0 & 296 \\
\hline FMC multiBic $\left(\mathrm{K}^{+} 4\right)$ & 140 & 4 & 1.5 & 0.5 & 113 & 0 & 0 & 35 & 0 & 0 & 1 & 0 & 298 \\
\hline FMC multiPlus $\left(\mathrm{K}^{+} 2\right)$ & 140 & 2 & 1.5 & 0.75 & 109.7 & 0 & 0 & 35 & 0 & 0 & 1 & 1 & 295 \\
\hline FMC Ci-Ca Dialysate K2 & 133 & 2 & 0 & 0.75 & 116.5 & 0 & 0 & 20 & 0 & 0 & 1 & 0 & 278 \\
\hline FMC Ci-Ca Dialysate K4 & 133 & 4 & 0 & 0.75 & 118.5 & 0 & 0 & 20 & 0 & 0 & 1 & 0 & 282 \\
\hline FMC Ci-Ca Dialysate K2 Plus & 133 & 2 & 0 & 1 & 115.75 & 0 & 0 & 20 & 0 & 0 & 1 & 1.25 & 278 \\
\hline FMC Ci-Ca Dialysate K4 Plus & 133 & 4 & 0 & 1 & 117.75 & 0 & 0 & 20 & 0 & 0 & 1 & 1.25 & 282 \\
\hline Gambro Hemosol BO & 140 & 0 & 1.75 & 0.5 & 109.5 & 3 & 0 & 32 & 0 & 0 & 0 & 0 & 287 \\
\hline Gambro Prism0cal & 140 & 0 & 0 & 0.5 & 106 & 3 & 0 & 32 & 0 & 0 & 0 & 0 & 282 \\
\hline Gambro Prism0cal B22 & 140 & 4 & 0 & 0.75 & 120.5 & 3 & 0 & 22 & 0 & 0 & 6.1 & 0 & 296 \\
\hline Gambro Phoxilium & 140 & 4 & 1.25 & 0.6 & 115.9 & 0 & 0 & 30 & 0 & 0 & 0 & 1.2 & 293 \\
\hline Haemofiltration solution 1 & 140 & 1 & 1.62 & 0.75 & 100.75 & 45 & 0 & 0 & 0 & 0 & 2 & 0 & 300 \\
\hline Haemofiltration solution 2 & 135 & 2 & 1.87 & 0.75 & 108.5 & 33.75 & 0 & 0 & 0 & 0 & 1.5 & 0 & 290 \\
\hline Haemofiltration solution 3 & 135 & 0 & 1.87 & 0.75 & 106.5 & 33.75 & 0 & 0 & 0 & 0 & 1.5 & 0 & 286 \\
\hline Haemofiltration solution 4 & 135 & 3 & 1.87 & 0.75 & 109.5 & 33.75 & 0 & 0 & 0 & 0 & 1.5 & 0 & 292 \\
\hline Haemofiltration solution 5 & 140 & 0 & 2 & 1 & 111 & 0 & 35 & 0 & 0 & 0 & 1.5 & 0 & 292 \\
\hline ACDA & 225 & 0 & 0 & 0 & 0 & 0 & 0 & 0 & 75 & 38 & 22.3 & 0 & 462 \\
\hline ACDB & 135 & 0 & 0 & 0 & 0 & 0 & 0 & 0 & 45 & 23 & 13.4 & 0 & 277 \\
\hline FMC Trisodium citrate $4 \%$ & 408 & 0 & 0 & 0 & 0 & 0 & 0 & 0 & 136 & 0 & 0 & 0 & 544 \\
\hline Gambro Prismocitrate 10/2 & 136 & 0 & 0 & 0 & 106 & 0 & 0 & 0 & 10 & 2 & 0 & 0 & 254 \\
\hline Gambro Prismocitrate $18 / 0$ & 140 & 0 & 0 & 0 & 86 & 0 & 0 & 0 & 18 & 0 & 0 & 0 & 244 \\
\hline
\end{tabular}

Abbreviations: $\mathrm{ACDA}=$ Acid Citrate Dextrose Solution A; $\mathrm{ACDB}=$ Acid Citrate Dextrose Solution B; $\mathrm{Ca}=$ calcium; $\mathrm{Cl}=$ chloride; $\mathrm{FMC}=$ Fresenius

Medical Care; $\mathrm{Mg}=$ magnesium; $\mathrm{Na}=$ sodium; $\mathrm{K}=$ potassium

was tedious, time-consuming, and error-prone. The designed for citrate-based treatment. Additional next evolution was to use online replacement fluid infusion pumps for continuous citrate administration generated from Gambro AK200 Ultra S (Gambro were required during treatment, and posed major Hospal, Stockholm, Sweden) together with post- safety problems. When the CRRT machine alarm dilution continuous venovenous haemofiltration sounds for bag exchange or for other mechanical with citrate anticoagulation using ACDA. The problems, all CRRT infusion pumps will stop advantage of this system was the flexibility of except for the pump used to infuse the citrate adjusting sodium and bicarbonate concentrations solution, which may result in the direct infusion with the replacement solution generated online. It of citrate solution into the patient. Nowadays, the also came at a lower treatment cost due to generation new CRRT machines have incorporated integrated of sterile replacement fluid via the online system..$^{32}$ citrate modules and specific protocols. Continuous However, generation of ultra-pure water is a pre- monitoring of citrate and ionised calcium levels requisite for implementation, and ICUs without together with computerised algorithms may further pre-installed water delivery and treatment systems improve patient safety and minimise potential sidewill be precluded from this treatment technology. In effects. ${ }^{33,34}$ Yet, successful implementation of the the recent 10 years, commercially prepared citrate- protocol requires focused and continuous training containing replacement solution and tailor-made for the involved clinical staff.

dialysate have become widely available (Table 2), and citrate-based CRRT has been widely adopted in different ICUs.

\section{Machine and protocol development}

Previous CRRT machines were not specifically

\section{Conclusion}

Citrate is a safe and effective anticoagulant for CRRT. Its advantages can be fully appreciated with a simple, well-devised and practicable protocol, and appropriate clinical staff training. 


\section{References}

1. Uchino S, Bellomo R, Morimatsu $\mathrm{H}$, et al. Continuous renal replacement therapy: a worldwide practice survey. The beginning and ending supportive therapy for the kidney (B.E.S.T. kidney) investigators. Intensive Care Med 2007;33:1563-70.

2. Davies H, Leslie G. Anticoagulation in CRRT: agents and strategies in Australian ICUs. Aust Crit Care 2007;20:15-26.

3. van de Wetering J, Westendorp RG, van der Hoeven JG, Stolk B, Feuth JD, Chang PC. Heparin use in continuous renal replacement procedures: the struggle between filter coagulation and patient hemorrhage. J Am Soc Nephrol 1996;7:145-50.

4. Hoffmann JN, Vollmar B, Laschke MW, et al. Adverse effect of heparin on antithrombin action during endotoxemia: microhemodynamic and cellular mechanisms. Thromb Haemost 2002;88:242-52.

5. Oudemans-van Straaten HM, Kellum JA, Bellomo R. Clinical review: anticoagulation for continuous renal replacement therapy-heparin or citrate? Crit Care 2011;15:202.

6. Chadha V, Garg U, Warady BA, Alon US. Citrate clearance in children receiving continuous venovenous renal replacement therapy. Pediatr Nephrol 2002;17:819-24.

7. Hartmann J, Strobl K, Fichtinger U, Schildböck C, Falkenhagen D. In vitro investigations of citrate clearance with different dialysis filters. Int J Artif Organs 2012;35:3529.

8. Oudemans-van Straaten HM, Ostermann M. Bench-tobedside review: Citrate for continuous renal replacement therapy, from science to practice. Crit Care 2012;16:249.

9. Tolwani A, Wille KM. Advances in continuous renal replacement therapy: citrate anticoagulation update. Blood Purif 2012;34:88-93.

10. Joannidis M, Oudemans-van Straaten HM. Clinical review: Patency of the circuit in continuous renal replacement therapy. Crit Care 2007;11:218.

11. Baldwin I. Factors affecting circuit patency and filter 'life' Contrib Nephrol 2007;156:178-84.

12. Hetzel GR, Schmitz M, Wissing H, et al. Regional citrate versus systemic heparin for anticoagulation in critically ill patients on continuous venovenous haemofiltration: a prospective randomized multicentre trial. Nephrol Dial Transplant 2011;26:232-9.

13. Oudemans-van Straaten HM, Bosman RJ, Koopmans M et al. Citrate anticoagulation for continuous venovenous hemofiltration. Crit Care Med 2009;37:545-52.

14. Fealy N, Baldwin I, Johnstone M, Egi M, Bellomo R. A pilot randomized controlled crossover study comparing regional heparinization to regional citrate anticoagulation for continuous venovenous hemofiltration. Int J Artif Organs 2007;30:301-7.

15. Kutsogiannis DJ, Gibney RT, Stollery D, Gao J. Regiona citrate versus systemic heparin anticoagulation for continuous renal replacement in critically ill patients Kidney Int 2005;67:2361-7.

16. Monchi M, Berghmans D, Ledoux D, Canivet JL, Dubois B, Damas P. Citrate vs. heparin for anticoagulation in continuous venovenous hemofiltration: a prospective randomized study. Intensive Care Med 2004;30:260-5.

17. Betjes MG, van Oosterom D, van Agteren M, van de Wetering J. Regional citrate versus heparin anticoagulation during venovenous hemofiltration in patients at low risk for bleeding: similar hemofilter survival but significantly less bleeding. J Nephrol 2007;20:602-8.

18. Zhang Z, Hongying N. Efficacy and safety of regional citrate anticoagulation in critically ill patients undergoing continuous renal replacement therapy. Intensive Care Med 2012;38:20-8.

19. Wu MY, Hsu YH, Bai CH, Lin YF, Wu CH, Tam KW. Regional citrate versus heparin anticoagulation for continuous renal replacement therapy: a meta-analysis of randomized controlled trials. Am J Kidney Dis 2012;59:810-8.

20. Liao YJ, Zhang L, Zeng XX, Fu P. Citrate versus unfractionated heparin for anticoagulation in continuous renal replacement therapy. Chin Med J (Engl) 2013;126:1344-9.

21. Khwaja A. KDIGO Clinical Practice Guidelines for Acute Kidney Injury. Nephron Clin Pract 2012;120:179-84.

22. Zheng Y, Xu Z, Zhu Q, et al. Citrate pharmacokinetics in critically ill patients with acute kidney injury. PLoS One 2013;8:e65992.

23. Meier-Kriesche HU, Gitomer J, Finkel K, DuBose $\mathrm{T}$. Increased total to ionized calcium ratio during continuous venovenous hemodialysis with regional citrate anticoagulation. Crit Care Med 2001;29:748-52.

24. Bakker AJ, Boerma EC, Keidel H, Kingma P, van der Voort $\mathrm{PH}$. Detection of citrate overdose in critically ill patients on citrate-anticoagulated venovenous haemofiltration: use of ionised and total/ionised calcium. Clin Chem Lab Med 2006;44:962-6.

25. Link A, Klingele M, Speer T, et al. Total-to-ionized calcium ratio predicts mortality in continuous renal replacement therapy with citrate anticoagulation in critically ill patients. Crit Care 2012;16:R97.

26. Ward DM. The approach to anticoagulation in patients treated with extracorporeal therapy in the intensive care unit. Adv Ren Replace Ther 1997;4:160-73.

27. Saner FH, Treckmann JW, Geis A, et al. Efficacy and safety of regional citrate anticoagulation in liver transplant patients requiring post-operative renal replacement therapy. Nephrol Dial Transplant 2012;27:1651-7.

28. Leung AK, Shum HP, Chan KC, Chan SC, Lai KY, Yan WW. A retrospective review of the use of regional citrate anticoagulation in continuous venovenous hemofiltration for critically ill patients. Crit Care Res Pract 2013;2013:349512.

29. Shum HP, Chan KC, Yan WW. Regional citrate anticoagulation in predilution continuous venovenous hemofiltration using prismocitrate $10 / 2$ solution. Ther Apher Dial 2012;16:81-6.

30. Balik M, Zakharchenko M, Leden P, et al. Bioenergetic gain of citrate anticoagulated continuous hemodiafiltrationa comparison between 2 citrate modalities and unfractionated heparin. J Crit Care 2013;28:87-95.

31. Leung AK, Yan WW. Renal replacement therapy in critically ill patients. Hong Kong Med J 2009;15:122-9.

32. Takatori M, Yamaoka M, Nogami S, et al. Online CHDF system: excellent cost-effectiveness for continuous renal replacement therapy with high efficacy and individualization. Contrib Nephrol 2010;166:173-80.

33. Szamosfalvi B, Frinak S, Yee J. Automated regional citrate anticoagulation: technological barriers and possible solutions. Blood Purif 2010;29:204-9.

34. Brandl M, Strobl K, Hartmann J, Kellner K, Posnicek $\mathrm{T}$, Falkenhagen D. A target-orientated algorithm for regional citrate-calcium anticoagulation in extracorporeal therapies. Blood Purif 2012;33:7-20. 